\title{
Notes on the genus Eotetranychus (Acari: Tetranychidae) in Italy and France with a redescription of Eotetranychus fraxini Reck, new record for Italy and Western Europe
}

\author{
ALAIN MIGEON ${ }^{1}$, VALERIA MALAGNINI ${ }^{2}$, MARIA NAVAJAS $^{1} \&$ CARLO DUSO $^{3}$ \\ ${ }^{\prime}$ Institut National de la Recherche Agronomique, Centre de Biologie et Gestion des Populations, Campus International de Baillarguet, \\ CS 30016, 34988 MONTFERRIER sur LEZ Cedex, France.E-mail: migeon@supagro.inra.fr; navajas@supagro.inra.fr \\ ${ }^{2}$ Istituto Agrario San Michele all'Adige, Via Edmondo Mach, 138010 S.Michele all'Adige (TN), Italy. \\ E-mail: valeria.malagnini@iasma.it \\ ${ }^{3}$ Department of Environmental Agronomy and Crop Science - University of Padua, Viale dell'Università, 16, 35020 Legnaro (PD), \\ Italy.E-mail: carlo.duso@unipd.it
}

\begin{abstract}
Until now eight species in the genus Eotetranychus were known from Italy and nine from France. This study reports the presence of two additional species in Italy: E. aceri Reck and E. fraxini Reck and one in France: E. uncatus Garman. New host plants are reported for E. rubiphilus Reck and E. aceri, and distributional and host plant data are recorded for several other species. E. fraxini was previously known only from Georgia and Hungary and is redescribed here.
\end{abstract}

Key words: Acari, Tetranychidae, host plants, Vitis vinifera, geographic distribution, Europe

\section{Introduction}

The family Tetranychidae is the best studied among the phytophagous Acari; however the related literature refers mainly to only a few species of economic importance. They remain poorly known in terms of biogeography and description of biological features, particularly concerning host plant ranges. Moreover, the identity of several species included in the family remains uncertain, many species being in need of redescription and many synonymies still remaining unresolved. In Western Europe new species are still being detected (Auger et al., 2003), and new species records have recently been reported for several countries (Navajas et al., 1996; Ferragut \& Escudero, 1999; Bolland \& Vala, 2000; Migeon, 2003; Migeon, 2005).

Among the Tetranychidae, members of the genus Eotetranychus have been widely studied (Jeppson et al., 1975). According to the literature the Italian fauna includes ten species of the genus (Bernini et al., 1995; Castagnoli \& Nannelli, 2003); however only eight of these are actually present in this country (Bolland et al., 1998). The species E. gibbosus (Canestrini) has been moved to the genus Platytetranychus (Bolland et al., 1998) and E. pomi Sepasgosarian is considered a synonym of E. pruni (Oudemans) (Wainstein, 1960). Both Bolland et al. (1998) and Auger et al. (2003) reported nine species of Eotetranychus in France.

Eotetranychus carpini (Oudemans) is a serious pest in European vineyards (Delmas \& Rambier, 1954; Ambrosi \& Lenarduzzi, 1959; Mathys \& Tencalla, 1959; Schruft, 1985). It has been observed throughout the Italian peninsula, Sicily (Bernini et al., 1995), and France (Delmas \& Rambier, 1954; Vila, 1985). While this species exploits a wide range of host plants (Rota, 1962; Laffi \& Ponti, 1997; Bolland et al., 1998) it appears to have a particular preference for hornbeam (Carpinus betulus - Betulaceae). Dosse (in Gasser \& Mathys, 1960) suggested the existence of two distinct forms of E. carpini in Europe, one occurring on Vitis vinifera 